\title{
Exploring Transnational Advocacy Networks for Environmental Sustainability
}

\author{
Andrieli Diniz Vizzoto*, Jorge Renato de Souza Verschoore, Iuri Gavronski \\ Unisinos Business School, Unisinos Business School, Porto Alegre 91330-002, Brazil
}

Corresponding Author Email: andrielivizzoto@edu.unisinos.br

https://doi.org/10.18280/ijsdp.160209

Received: 31 October 2020

Accepted: 16 January 2021

\section{Keywords:}

advocacy networks, nongovernmental organizations, environment, sustainability

\begin{abstract}
This study aims to explore papers and assess how they have been addressing TAN features to understand better and explore a structure for the effectiveness of transnational advocacy networks (TANs) for environmental sustainability. Based on data collected, papers on the thematic of transnational advocacy networks for the environment were selected and explored to understand better what features are shown and under what light. Transnational advocacy networks for environmental issues are common in the literature, as the topic draws the attention of nongovernmental organizations. Many of the papers explore at least one of three pillars among the results, and frequently more than one is brought up into theoretical and empirical discussion. These results highlight specific features among each of the characteristics, building a framework so that TANs may have a path to structure their activities to achieve their goals more effectively. Further studies may advance this knowledge in practice. This study seeks to contribute to the existing literature from a theoretical perspective, integrating and exploring the dimensions of transnational advocacy networks and considering a possible structure to improve their results.
\end{abstract}

\section{INTRODUCTION}

The environmental instability and economic issues have been promoting situations such as mass migration, pandemics, global warming, wars over natural resources, and social values that may dictate the way society behaves, among others [1]. Hence, society's involvement is of great importance, from individual actions to organizations, institutions, and governments. Civil society organizations have emerged in recent years, emphasizing social issues such as gender, human rights, urban slavery, and environment, rather than class-based interests, as it was at their very first beginning. Some of these movements are organized in the form of nongovernmental organizations (NGOs) and advocacy networks, which are organizations seeking to address specific common interests for the whole globe. Amongst those organizational forms, there are the transnational advocacy networks (TANs), which may be conceptualized as networks resulting from interactions among actors at various levels from local communities to international issues [2].

Hence, when social institutions are absent, but people recognize their role as citizens and part of nature, civil society organizations arise to provide the awareness and norms that are lacking or failing. One of these possible organizations is in the format of advocacy networks: a voluntary, reciprocal, and horizontal form of organization, with individual or collective actors that decide to work to achieve a common goal, which has to be a common objective for social purposes [3].

According to Diaz [4], "Networks are a quintessential example of shifting territories, embodying new organizational forms that can change and adapt continuously. As a consequence, they represent spaces and organizational forms that enable and create the future". Thus, the networks represent the future for society and its organizations. However, it is also crucial to understand the present to acknowledge future steps for studies and managers to contribute to the advance of the field.

Therefore, networks are structures that gather many characteristics that are of value to study and understand. We believe networks may be one of the most used forms to connect people, organizations, and projects. Hence, the study of TANs is relevant as it broadens the knowledge of effective forms of managing such networks.

One subject directly connected with our future is environmental sustainability. We define sustainability by the concept of sustainable development: the current generation's ability to meet its needs without compromising future generations' abilities to meet their own needs [5].

Lim and Pope [6] suggest that the rise of the corporate social responsibility movement has increased company policies addressing social issues, mainly related to workers, human rights, supply chains, and the natural environment. Their study finds that firms crossing national borders for global markets incorporate social responsibility in their structure [6]. Yang and Zang [7] recognized that sustainability is a topic that must concern many organizations, especially the environmental dimension.

As suggested by Dayoub et al. [8], environmental conservation has been a vital topic for many businesses. Theories must follow the direction of trying to integrate social, cultural, sustainable, and economic factors. Thus advocacy networks should work well as a possible way to integrate different actors and to address issues on levels that single individuals or businesses may not fully accomplish. Therefore, it seems that sustainability is a suitable subject for transnational advocacy networks, as they have at their core the 
idea of being global.

Although the subject of environmental care and networks are relatively recent, few studies are addressing the results or shaping of these structures [9]. Keck and Sikkink [10] suggested that some characteristics may help TANs be more successful in their actions: strong relationships among their members, coordinated information flows, and actors with multiple roles/levels within the network. Hence, recognizing how transnational advocacy networks for the environment are structured through practical studies is essential to create a format for their goals. This paper aims to explore the literature and assess how it has been addressing TAN features to provide a better understanding of advocacy networks management structures.

It is very suitable to study TANs under the light of their features, trying to connect how managing such networks could be more effective, which specific characteristics those networks should be more attentive to when planning their activities to achieve their goals. Additionally, environmental issues arise more often, either directly (e.g., in oil spills) or indirectly (e.g., in climate-related events or pandemics that might surge from the environmental imbalance), and turn human lives upside down. Consequently, understanding how networks may help address environmental topics may provide a better way to use networks' power towards addressing this pressing issue.

\section{THEORETICAL BACKGROUND}

Advocacy networks are social movements or nongovernmental organizations. However, they also include individual actors and groups from the private or public sectors, foundations, education institutions, intellectuals, media, and a vast spectrum of possible actors. Advocacy networks shape into transnational advocacy networks (TANs) as they address international subjects or form a network with multiple actors from different countries, then act on an international scale. The main goal for these transnational advocacy networks is to create a boomerang pattern, which is achieved by activating a transnational network focused on the issue that can exert pressure on a global level, reaching many countries [10].

Transnational advocacy networks generally address issues that may affect the globe, supported by multiple actors spread throughout the world, or at least more than within one country's borders, where they act together to manage local or global problems [2]. For this study's purpose, transnational advocacy networks will be understood as the collective of individuals, organizations, or others and selected those that attempt to solve or address environmental problems.

TANs may be more effective when their objectives are directed to end or minimize hazardous situations that affect vulnerable individuals or situations, such as the destruction of nature, native peoples, and cultures [10]. Given their orientation to action, identifying TANs' characteristics helps understand and identify what actions will occur in the future [4]. Thus, TANs play an active role in global patterns, making it even more critical to unveil their network structures and ties among actors, their use of tools and techniques to create and follow different strategies, and the knowledge they form together [11]. The theory provides an external perception that some features are more important in a transnational advocacy network structure, therefore such features should be taken into consideration when tracing management aspects for these networks, seeking better results.

Keck and Sikkink [10] advocated for actors from multiple levels to gain strength as a network. Diverse actors may create diverse strategies to follow network objectives. As organizations have leading strategies, networks do the same, having actors as connections. The stronger these connections, the stronger the network, and the better are the results and reach. These actors involved in the process may be inside actors or connections and external stakeholders, such as partners, public figures, and suppliers.

A second dimension to consider for TANs' structure is information flow. Transnational advocacy networks must pay attention to this flow as their actors are spread along with distant geographical places, and conveying a unified message sends the network ideas to other publics. The information flow helps to create a strong campaign towards the network goal [10]. Though catalytic events are better to gather more people to the cause, it is hard to keep those people motivated and pass along the same message, requiring organized action from the advocacy network to coordinate the pieces of information.

Strong ties are created between similar actors, creating a redundant information flow. Usually, these actors have many common factors and knowledge, which helps create a strong bond. However, for Granovetter, it is not necessarily an advantage for the network [12]. Contrariwise, Keck, and Sikkink [10] suggested strong ties are necessary for TANs, especially environmental advocacy networks. For the latter, the goal of nature preservation may gather people, but to keep them together for as long as it is necessary for the network is a different and greater challenge. Thus, strong ties are essential to keep TANs along the road of their course of action, maintaining different and geographically distant actors together.

Environmental issues improve organizations and society's ability to deal with changing, creating opportunities, and providing information about possible problems [13]. Thus, environmental issues are relevant for the planet and, consequently, for people and organizations, as both of them depend on having a planet to exist. Research about sustainability $[14,15]$ indicates that people and organizations have a substantial role in keeping our environment healthy. Combining those two perspectives of organizations and environment, advocacy networks concerning sustainability for the planet seems an arrangement that creates an agenda to talk about social responsibility for both individuals and organizations, as both of them depend on the same planetary environment [16].

In sum, mastering how networks organize themselves tactically facilitates to create better management towards the network objectives, to organize a dialogue with the community, mainly when the network results are beneficial and these results cause changes in the community development, as it is in many advocacy networks. Therefore, studying and understanding advocacy network management features provides a clear format of important characteristics that should be attended by advocacy network managers. We do believe that studying advocacy networks may assist the networks field, creating not only this new framework for pre-existing facilitating other network formats to have a pre existing style from where to start their managing plans. These features may indicate the needs of a network in terms of what is necessary to arrange, rearrange, plan and develop in order to better achieve steps leading to the network success - which we understand as achieving the network goals. 


\section{METHOD}

Overall, the methodology chosen was qualitative; mainly a literature review based on Keck and Sikkink's [10] advocacy networks features. According to Ramos-Rodriguez and RuizNavarro [17], the study of articles published in journals is considered as a recognized knowledge, as the articles have passed through the critical review by other researchers and were approved. For that reason, they are a good parameter for evaluating the knowledge base that is being developed in some issues. Also, in Fergnani [18] mapping literature is a possible way to visualize past academic researches and create inferences about gaps and fragmentation; it enables us to understand conceptions for future researches.

This search was conducted in the database Web of Science - looking for the keywords "transnational advocacy networks" AND "sustainability," focusing on articles that combined those topics. The results were broadened to include other possible variations, replacing the word sustainability for "environment", "green", "climate". The search was limited for the years from 2000 on, as the study chosen as our compass for transnational advocacy networks was published by Keck and Sikkink in 1998.

The primary search found 58 papers related to the searching pattern, and then there was a researcher filter, which is: excluding double results, then the screening process was through the titles and the abstract. We screened those articles which have in their core results transnational advocacy networks advocating for environmental issues by reading their full text and checking whether these studies were analyzing features described by Keck and Sikkink [10] for the characteristics of TANs. The papers were then analyzed as follows, according to Figure 1:

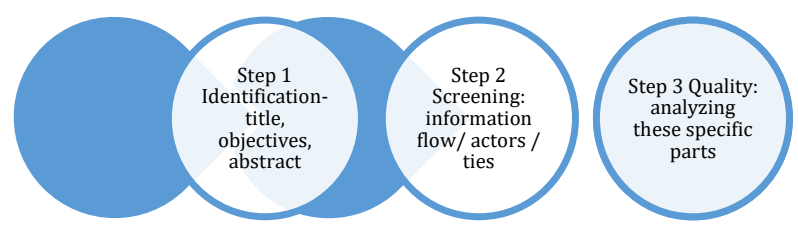

Figure 1. Research steps

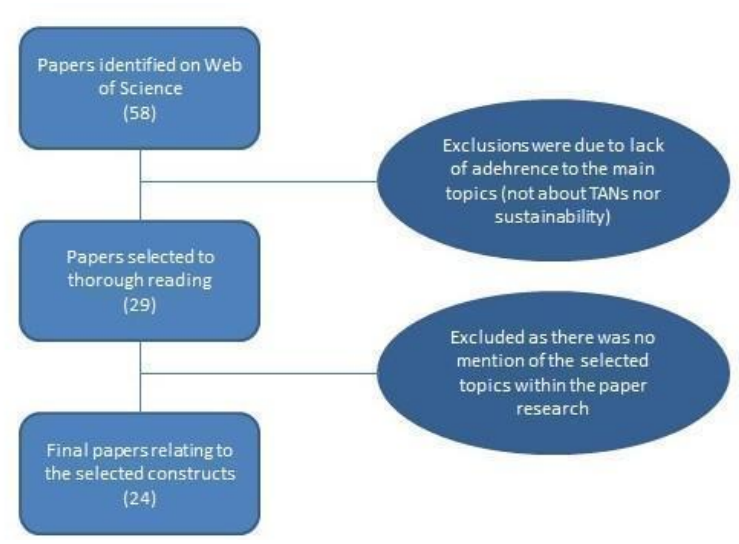

Figure 2. Literature results

From the primary 58 papers, 29 were identified as fitting to this research objective. The excluded ones presented other non-related themes: transnational advocacy networks for other causes such as human rights, child activism, and other social movements. Some of them could not be included as TANs, but our initial search retrieved them because there were some citations about TANs during the main writing. The final 29 papers were then read searching for the specific features of advocacy networks: information flow; multilevel actors; strong ties.

After selecting the papers, we read then to analyze the specific parts where the authors describe something related to the specific transnational advocacy networks features: information flow, multilevel actors, and ties among the members and partners of the network, as Figure 2 illustrates.

The resulting 24 paper present their relevant results in the following section, showing that about transnational advocacy networks there is a path for structure and understand network management and develop future studies.

\section{RESULTS}

The emergence of a global awareness network about certain issues and the larger inertia of some traditional social institutions (for example, governments) or lack of attitude from those to create and sustain traditional norms is one of the possible globalization effects [19]. When traditional social institutions fail, the field for advocacy networks, as well as any other civil society organizations, becomes fertile.

Studies have shown the importance of the environment, for the planet, and, consequently, for people and companies. So, more than ever, many studies on environmental preservation have arisen indicating people's and companies' role. Networks play a central role, having organizations and individuals working together. Croxatto, Hogendoorn, and Petersen [11] argue that scholars should pay attention to global patterns of network structures, analyzing their ties, tools, and techniques that distinguish their strategies.

This study shows that transnational advocacy networks for sustainability is an underdeveloped subject in the literature, and there is not a consensus about what structure is better suiting for managing TANs. Many of the articles, though used Keck and Sikkink's [10] characteristics as part of the study references, were not directly concerned about studying any of the parts these authors selected as relevant for a TAN.

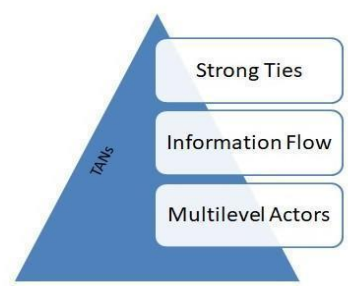

Figure 3. TANs features based on Keck and Sikkink (1998)

Based on these specific features, demonstrated in Figure 3, that follow no specific order, some papers presented corroborations to the authors' previous study, many of them focused on a single part, although citations about the importance of these characteristics were common, this research was more interested in a better understanding of transnational advocacy networks management structures through the literature results.

\subsection{Information flow}

Scholars had long ago recognized information as an 
important action for any organization. For transnational advocacy networks, it's even more important to have an information flow that could tie actors together, as they are apart, many times, by great geographical distances.

The novelty of information when considering this topic with TANs is their ability to mobilize information in a strategic manner, creating new issues, persuading, pressurizing, and gaining leverage over more powerful organizations. Keck and Sikkink [10] suggest that information flow is necessary to create a strong campaign, although a catalytic event may help gather people to the cause, keep them together, and speaking in unsound about the network goals that require more coordination. Therefore, information is not only the ability to communicate within the network but to communicate in a fashion manner, which requires management and planning.

The word information was abundant in many of the papers of our sample. Many times it was not adding anything new about it, but the mere recognition of its importance as it is explicit in Never and Betz [20] study about the influence of the domestic green industry, the ratio of fossil fuels to financial power, the international negotiating position, and the environment in Brazil, China, Indonesia, South Korea, Mexico, and South Africa. The authors cite the National Committee of Climate Change as an example of a one-way information platform, which highlights the importance of any network dealing with this type of situation, where discussion is not open, to have a clear information flow, whether to pass along the correct message or to not be deceived by the wrong message.

In its research, Gerber [21] suggests that transnational advocacy networks play an important role in tree plantation conflicts, especially being activists on legal issues, and some of the most known TANs are the ones which can exchange information internationally, exploring a strong case in favor of information flow to strengthen TAN relations and achieving better results.

Corroborating with that, Herring's study [22] states that "within networks and between networks, intermediaries translate information into terms conducive to political action". It enhances the idea that information is the key to actors' actions towards their goals, possibly leading to stronger and collective actions formulated by the network.

Storytelling is also important, as TANs use the information to mobilize actors, using real-life stories raises awareness about the effects of any harmful problem on real people [23], it helps to understand the actors and their motivations, as well as creating a deep empathy level for other partners to understand or support the cause. It is noteworthy to mention that information, although key in many studies, although cited for those same many studies as shown by this research, it is rarely the center of the research topic. This may occur because the information is a difficult topic to research alone, as it may sound subjective or difficult to measure. And it really may present itself as a challenging feature for researchers, as information is cited by almost all papers, but not studied by all of them as central to the transnational advocacy network. But it is clear by the excerpts above that many authors researched information flow within the network to understand its actions, sometimes also to understand the actors amongst the network.

\subsection{Strong relations}

In a similar direction to Granovetter's [12] study about weak and strong ties - which suggests strong ties are held among similar individuals in a network, therefore they may create redundant information as the actors tend to have similar backgrounds. Thus they are not an advantage - Keck and Sikkink [10] suggest the relationship among actors in a network is of great importance. Specifically addressing environmental advocacy networks, the authors highlight the importance of international events that may help mobilize people, put them in contact with each other, creating bonds that may strengthen the network. In a divergent direction than Granovetter's [12], they do not think strong relations may create redundant information, but see those as essential for the success of a transnational advocacy network, as many of the actors may be separated by great distances, in different countries, mainly when the cause is an environmental issue that goes across the globe, creating strong relationships amongst different actors is vital for the continuity of the TAN.

Many papers had some citations about strong relations, either from Granovetter [12] or other examples of studies that demonstrated his approach or even other authors. Castillo et al. [24] suggest that time creates the emotional intensity and the confiding necessary for creating ties among organizations or people, improving the services they can mutually provide. For the purposes of this paper, the results in this subsection include either ties or relations, as many studies consider them as synonyms.

In her study, Dupuy [25] investigated the adoption of laws requiring firms or states to ensure that mining translates into real, positive social, and economic gains for mining-affected communities. The study finds that improving relations with the community was one of the best ways to ensure the quality of the community developed projects and secure a license to operate, stressing the importance of strong relations among different actors. This paper also has one specific topic to describe the results about institutions and actors and financial flows, demonstrating how major these subjects are when addressing the results achieved by any transnational advocacy network.

In a paper investigating liberal forms of resources governance and emerging struggles over control of sea space between coastal fishers, the oil industry, and government authorities, Quist and Nygrem [26] focus on the role of relations among different actors involved in a transnational advocacy network, although it does not evaluate whether these relations are weak or strong. However, it stresses how these relations may influence the final result of network actions.

Emphasizing relations, Hadden and Jasny [27] focus on social ties among networks, specifically endorsing Keck and Sikkink [10] by finding results that show how ties serve as a channel among actors for communication and sharing principles, which are bases for an advocacy network. The relations among actors are an opportunity for communications, creating shared plans, visions, and social cohesion [27]. Also, friendly relations with the whole partners that are in the context of the advocacy network is advisable, according to Schapper [23], as these receptive relations may help the network to achieve its goals, have a better entrance in certain circles, and having contact with decision-makers.

Even though strong relations may not be as relevant to all forms of networks, as many may benefit from Granovetter's weak ties and the advantages of diversity amongst the members of the network, understanding these bonds and how they are formed could help managers to improve and incentivize activities in order to create and strengthen these ties. Also, whenever strong ties are not relevant or do not bring 
more knowledge or any kind of leverage for the advocacy network, avoiding creating them and investing in different plans to create a friendly environment for different ties according to what are the advocacy network needs.

\subsection{Actors}

Transnational advocacy networks include a diversity of actors, ranging from international and domestic NGOs, local social movements, trade unions, churches, and intergovernmental organizations. The same way an organization uses a range of strategies to reach their goals, so does a TAN, using their actors as links, the stronger the links, the stronger the network. Keck and Sikkink [10] advise that actor characteristics are an important part of the conditions that make a network more or less effective. Multiple levels of actors may bring strength to the TAN, probably as they will bring a diverse range of strategies to create links and act on strategies to reach the goals.

Considering the economic current paradigm, companies are called to take responsibility for their actions more often nowadays, to create solutions to the problems they create for the environment by using natural resources, these enterprises are integrated into the community [1]. Therefore, the presence of different actors is not only important for the advocacy network in order to bring diversity and different resources, but also these networks may work for the companies as a strategy to gather resources with other actors and create a positive impact that will allow them to strategically address the environmental issue.

Baigorrotegui [15] is one example of actors' roles in transnational advocacy networks. The study was interested in the actor's role in shifting government paradigms, as electric power generation is one of the main interests in many countries. The study was conducted in Chile but investigated the actions of TANs, as other actors were involved, forming a network from different countries concerned about the environmental questions arose by the ideas on electric power generation, as it is many times something that affects the environment. The study claims something similar to Keck and Sikkink's [10] main idea that multiple and diverse actors create a stronger network. Thereby, it is suitable for transnational advocacy networks to broaden their actornetwork, searching for different levels of actors, such as companies, NGOs, political and governmental partners, individual actors, and so forth.

A case study conducted by Christoff and Sommer [2] assessed the potential of TANs to create sustainable and environmental changes at a local level and concludes that the involvement of several international and domestic actors promotes a synergy that stimulates the work of the advocacy network, once again showing through findings that actors in different levels are an advantage for reaching effectiveness when it comes to networks.

Considering actors and strong ties, within the results of this research, they seem to be two factors strongly interconnected, and probably, in many cases, they will be affected by the same activities. Therefore, if the network decides to plan and develop activities thinking about one of these features, it is likely the results will impact both of them.

\section{DISCUSSION}

The network scenario found by this study is one where voluntary efforts prevail in many cases, although it is possible to find many cases where public and private sectors work side by side (government and companies) towards emerging problems that affect the economy of a certain place $[25,28]$.

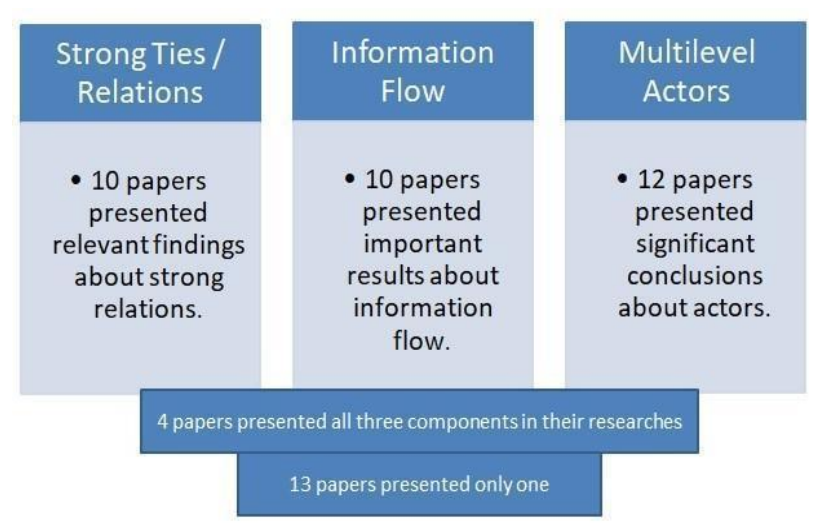

Figure 4. Literature analysis

These studies carried many possibilities to create, share, and adapt models worldwide that assess the real results and reach of transnational advocacy networks. Figure 4 shows that they have specific approaches to one or more topics. One study that presented all three configurations in its findings was carried out by Schapper [23], contributing to understanding environmental policy by exploring international policy changes, analyzing politics and the involved actors, their interactions, and how those processes were aligned with transforming practices and chancing policies. The very definition of Schapper's [23], studies encompass all three characteristics, analyzing the change of information, the role of actors, and ties among them.

The study carried out in 2020 aims to contribute to environmental and climate policies, exploring multi-level learning through local experiences to make international policy changes, also trying to analyze the politics behind this learning process, specifically putting under the microscope the strategic use of information, symbols and accountability mechanisms. The information has an important role in Schapper's [23] study, as it is the central piece when the author analyzes how a policy may change around the globe and how non-state actors use their resources to teach basic norm principles linked to environmental issues to state actors. So, the actors involved in the process need to be careful and aware of the information they are using because they are acting in different levels of power - state and non-state actors communication. One strategy highlighted is sharing stories, actors who were successful in creating human rights or environmental policy that was beneficial for the network are encouraged to share their stories and cases to raise awareness.

Addressing the strong ties, Schapper [23] suggests that building friendly relations among different actors in the strategy which achieved the most success, through these positive relations the advocacy networks were able to negotiate policy more easily. It is possible to infer that creating relations within actors who are involved in the same process of advocating for a cause makes the communication process easier, and probably creates an environment where ideas can be shared in a more respectful and deep manner. Also, the studied networks presented a hybrid quality, with very diverse actors, working in different scales, varying their institutionalization degree and their position inside the advocacy process, which enrichens the network experience 
[23].

All these characteristics presented in Schapper's [23] research are aligned with the Keck and Sikkink [10] study, which reinforces that when considering transnational advocacy networks, maybe we will find other important features, but managers should pay careful attention to the three pillars that will most likely bring success to the network goals: multilevel actors, strong ties and information flow.

Analyzing a timeframe, the studies presenting actors' characteristics seemed to be the latest ones, raging mainly from 2015 to 2020. Studies about ties verge mainly in 2015 and 2016. Information flow is the subject presenting the oldest studies, from 2006 up to 2011 presenting some range of researches in this topic. Probably because the information is a widely known feature of organizations, although it does not mean the issue has drought its contributions by now. Studies indicate that information is a feature to be managed as networks must harmonize their discourse with community and corporations [25] and translate information into political action to conquer their goals [22]. These are indicators that advocacy networks must commit to managing information in a way that enhances the network's ability to be effective, as it seems that information works as a kind of glue, keeping actors together. This is a very important role, as transnational advocacy networks are composed of multiple actors and from different places, when keeping the network discourse, as well as managing the right information about the network to reach all the interested actors is a crucial part of organizing and developing the network activities carried on in order to achieve its goals.

In the actor area, the multilevel of its description is very well absorbed by the very own particularity of a network: multiple actors, whether they are individual actors or organizations. However, in the case of a transnational advocacy network, it is also necessary to consider governmental and nongovernmental actors [29]. Managing such actors is an important balance as they may create an opportunity for the network to dialogue with different spheres of the globe, whether national or international, private or state corporations, broadening the range where the network is able to act.

Considering the strong ties, Sippl [30] ponders about the intentionally created relations between actors in a network, questioning yet if the strength and nature of those ties should be required to what extent. Keck and Sikkink [10] suggest strong ties are an important start point to TANs, but one has to wonder whether the new technologies, with social media achieving many people around the globe, may not propitiate a new type of ties, where the strength may be replaced by shared values, common goals among actors. Thus, the Granovetter [12] approach of strong and weak ties could be applied, where shared values would create the link between actors that strengthen the tie and keeps the network strong with a diversity of actors.

One very relevant study to further the ties within networks subject was conducted by Koslinski and Reis [31], where the findings suggest there are divisions among ties, and these divisions guarantee more support for the organization. The authors suggest five types of ties may be found in transnational advocacy networks: providing money, named partner, directly involved, providing non-monetary resources, and reported to. Each of those has its own importance to create a stronger and more diverse network, able to achieve its goals through different paths, using these different ties to create advantages in relations, moreover, they guarantee integration and diversification.

One characteristic that may be included in these models is mentioned by Feldman [32], where he suggests that one important subject that networks - and probable organizations as a whole worldwide - will have to address promptly is knowledge, as embracing global environmental governance through partnerships is an activity that requires shared information and exchange of ideas between local governments, non-governmental organizations and researchers.

These results show that many transnational advocacy networks studies, aligned with Keck and Sikkink [10], balance some communication flow - demonstrating that many researchers in the field understand the importance of a clear communication path, especially when you have many actors involved with the same network - with actors of different roles. Therefore, managing these characteristics should be one possible focus for TANs, as they could lead to better results, higher effectiveness, and reaching the important goals carried out by the network.

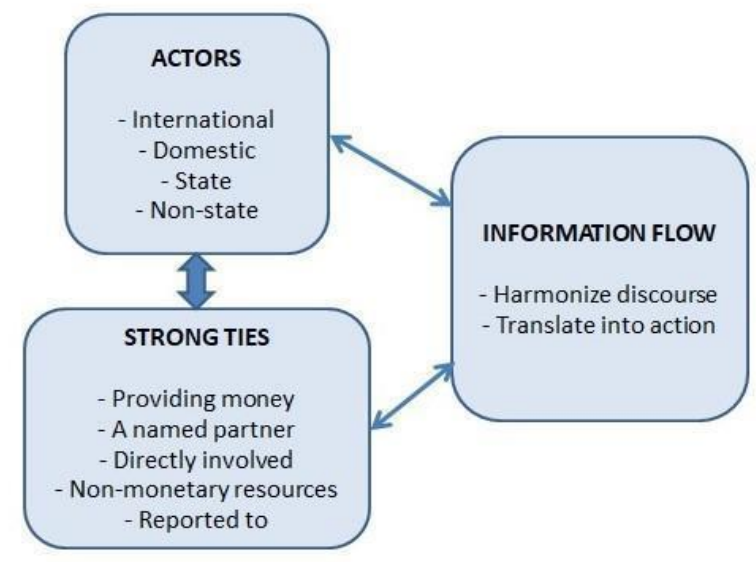

Figure 5. TANs management characteristics

Figure 5 shows the literature contributions to better understanding the management features for transnational advocacy networks. Considering that the TANs in this study where all connected with the environment, it is possible to say that a network interested in organizing its characteristics to better achieve its results, as proposed by Keck and Sikkink [10] and corroborated by many scholars, should take into account the spheres of its actors, ties, and information. At each of those, there are small particles to manage, as compartmentalize the actors and its ties, as a way to understand how to treat each of them, what scale they can act properly, what advantages they bring to the network, and even how to communicate with each of them. For the information characteristic, it is important that the advocacy network work within two fronts: harmonizing the discourse, considering its many different actors, and translate information into action, which is planning and practicing activities with its members in a coordinated manner, in order to achieve its goals more effectively. Figure 5 also shows that relations between actors and ties are much stronger, one cannot live without the other, whereas information flow is another category, but a binding one, it is through the harmonizing of information that all actors tend to understand the path indicated by the network to be followed, the plan to reach the goals.

At the beginning of this article, we said that environmental problems are generally managed by institutions that arise from initiatives aiming to fill the void created by the lack of social norms that may occur when the society faces problems that it 
is not yet prepared to solve or faces a situation where it lacks tools to understand how to behave with it. Possibly, as much of the literature researched in this paper is studying emergent countries' situations, it is a noticeable fact that transnational advocacy networks arise strongly in developing countries. It is worth stating that some studies [28, 33, 34] have developed their research in European or North American countries, but are few representatives of it. Never and Betz [20] focused their research especially in emerging regions, and it seems to be very fertile soil for sustainability actions, especially towards the environment. Ratten, Ferreira, and Fernandes [35] affirm that there are many differences when considering studies with emerging economies, the ability to face changes is completely different, the challenges they encounter is not only approached from different cultural and social aspects but also from different economics, which should be considered when thinking about TANs as well. Surely enough, developing countries represent a different reality when it comes to social institutions representation, government communication, and environmental policy. Social institutions represent a moral compass that guides society through collective social behavior, therefore, it is expected that in developing countries we will find many more social institutions that are not linked to the government, and many issues that are addressed in developed countries by governmental actions, will be tackled by nongovernment actors in developing countries. Thus, developing countries provide a fertile soil where structures as transnational advocacy networks find a place to fight for their goals of helping the community, and find a space where the lack of governmental forces give these networks more flexibility to act.

It is common to find transnational advocacy networks that are mostly based abroad, acting environmentally in developing countries. One important feature highlighted by this research findings is that multilevel actors are important for a network success, thus, creating bonds with locals is one of the strategies TANs that act in different countries should take into action. Especially those who deal with developing countries, not only to improve the information flow, other of the management features that should be taken into careful consideration but also to know the local culture and improve the relations among actors, creating strong ties that will help to assure that the network actions will be aligned with its goals.

Some issues were not addressed at all within the papers researched by this literature review, as the role of wellestablished advocacy networks, as World Wild Life or Greenpeace, for example. This may be an indicator that studying those big initiatives is not so interesting as knowing the process as a whole, mainly when the subject still needs to be understood from its core, its beginning actions, and what is possible to create to reinforce transnational advocacy networks activities.

\section{CONCLUSION}

Advocacy networks are social movements or NGOs, including individuals or groups from the public or private sector, foundations, academia, intellectuals, and the media They may act nationally, regionally, and internationally, tend to focus on mobilization and strategic dissemination of information to change the behavior of governments, private firms, or international organizations towards some specific purpose. These purposes are usually related to some value or ideal that social institutions are unable to solve or to address immediately, due to rapid changes in society or the inability of the traditional social institutions to follow or deal with these changes.

After searching through the selected 24 papers, this study shows that most environmental studies about TANs are held in developing countries, some papers were broader on the environmental topic, addressing climate change as a whole or globe heating. But most of them were very specific cases, and in consonance with Keck and Sikkink's work, emphasizing the roles of different actors and strong relations and good information flow so that some transnational advocacy networks could act on these environmental issues investigated. Actions take place over and in networks, analyzing these patterns allows a better possibility to intervene in the network to change it and reach future goals [4], delineating the tomorrow.

The literature shows a path of studying and managing some specific characteristics of transnational advocacy networks based on Keck and Sikkink together with new divisions. For the construct of actors, it was added the fact that they have multiple levels divided into international, domestic, state, and non-state. The ties received new five types that categorize them according to the specificity that the relationship has in the network. This theoretical frame (Figure 5) adds new layers that demand more studies to show whether these constructs maintain themselves as features for achieving effectiveness in TANs, as well as if there are other additions coming from new empirical evidence. These results show a possible path for future research, specifically testing the framework, assessing if those are important characteristics for reaching better results, to check whether its activities are generating the impact expected in the community, and engaging their partners. Also, it would be very interesting to analyze the impact of storytelling as a strategy to reinforce information flow, how much does it really works as motivation and engaging strategy for different actors, especially when dealing with transnational advocacy networks, a network where we find actors from different cultures. Does the story of one success from a different place have the same motivational impact aimed by the TAN on different actors? Studies about transnational advocacy networks governance are scarce, more than managing and planning and developing strategies, how to govern a network that is comprised of so many different actors that are many times spread across different countries? Should TANs by their very nature have shared types of governance? Or centralizing some decisions is the best way to guarantee the information flow to be the same? Another future study to consider would be the role of the different types of actors and different types of ties, studying how each one of the impacts on each other and if there are actors more incited or even pushed away by some types of ties.

Its database limits this study, the period analyzed, the specific words used for searching papers, and the constructs used to analyze the results. We suggest more researchers could broaden the understanding of how TANs are being investigated and what the evidence is coming from empirical studies for future researchers.

\section{REFERENCES}

[1] Guinot, J. (2020). Changing the economic paradigm: Towards a sustainable business model. International 
Journal of Sustainable Development and Planning, 15(5): 603-610. https://doi.org/10.18280/ijsdp.150502

[2] Christoff, P.S., Sommer, J.M. (2018). Women's empowerment and climate adaptation in Gurajat, India: A case-study analysis of the local impact of transnational advocacy networks. Sustainability, 10(6): 1920. https://doi.org/10.3390/su10061920

[3] Keck, M.E., Sikkink, K. (1999). Transnational advocacy networks in international and regional politics. International Social Science Journal, UNESCO, 51: 89101.

[4] Diaz, J.A.R. (2009). Networks and the future: A new methodological approach to envision and create the networks society of tomorrow. Futures, 41(7): 490-501. https://doi.org/10.1016/j.futures.2009.01.004

[5] Brundtland, G. (1987). Report of the world commission on environment and development: Our common future. United Nations General Assembly document A/42/427, $1-4$.

[6] Lim, A., Pope, S. (2020). Three types of organizational boundary spanning: Predicting CSR policy extensiveness among global consumer products companies. Business Ethics: A European Review, 29(3): 451-470. https://doi.org/10.1111/beer.12266

[7] Yang, F., Zhang, X. (2017) The impact of sustainable supplier management practices on buyer-supplier performance: An empirical study in China, Review of International Business and Strategy, 27 (1): 112-132. https://doi.org/10.1108/RIBS-08-2016-0043

[8] Dayoub, B., Yang, P., Dayoub, A., Omranl, S., Lil, H. (2020). The role of cultural routes in sustainable tourism development: A case study of Syria's spiritual route. International Journal of Sustainable Development and Planning, 15(6): 865-874. https://doi.org/10.18280/ijsdp.150610

[9] Kadirbeyoglu, Z. (2005). Assessing the efficacy of transnational advocacy networks. In: Environmentalism in Turkey: Between Democracy and Development? Eds. F Adaman and M. Arsel. Aldershot: Ashgate.

[10] Keck, M.E., Sikkink, K. (1998). Activists Beyond Borders: Advocacy Networks in International Politics. Ithaca and London: Cornell University Press.

[11] Croxatto, L.S., Hogendoorn, D., Petersen, A.C. (2020). How networked organizations build capacity for anticipatory governance in South East Asian deltas. Futures, 116 : 102512. https://doi.org/10.1016/j.futures.2020.102512

[12] Granovetter, M. (1973). The strength of weak ties. American Journal of Sociology, 78(6): 1930-1938.

[13] Al Khattab, A., Aldehayyat, J., Alrawad, M., Al-Yatama, S. (2012). Executive's perception of political-legal business environment in international projects. International Journal of Commerce and Management, 22(3): $168-181$ https://doi.org/10.1108/10569211211260328

[14] Cezne, E. (2019). Forging transnational ties from bellow: Challenging the Brazilian mining giant Vale S.A. across the South Pacific. The Extractive Industries and Society, 6(4):

1174-1183. https://doi.org/10.1016/j.exis.2019.10.007

[15] Baigorrotegui, G. (2019). Destabilization of energy regimes and liminal transition through collective action in chile. Energy Research \& Social Science, 55: 198-207. https://doi.org/10.1016/j.erss.2019.05.018
[16] Pocoock, M.J.O., Evans, D.M., Fontaine, C., Harvey, M., Julliard, R., McLaughlin, O., Silvertown, J., NezhadTamaddoni, A, White, P.C.L., Bohan, D.A. (2016). The visualization of ecological networks and their use as a tool for engagement, advocacy and management. Advances in Ecological Research, 54: 41-85. https://doi.org/10.1016/bs.aecr.2015.10.006

[17] Ramos-Rodrigues, A.R., Ruiz-Navarro, J.R. (2004). Changes in the intellectual structure of strategic management research: A bibliometric study of the Strategic Management Journal, 1980-2000. Strategic Management Journal, 25(10): 981-1004.

[18] Fergnani, A. (2018). Mapping futures studies scholarship from 1968 to present: A bibliometric review of thematic clusters, research trends, and research gaps. Futures, 105: 104-123. https://doi.org/10.1016/j.futures.2018.09.007

[19] Gomes, J.B. (2018). As redes transnacionais de advocacy em direitos humanos: atuação em torno da "questão palestina”. Dissertation (masters). Programa de PósGraduação em Ciência Política. Curitiba, Universidade Federal do Paraná. https://hdl.handle.net/1884/58010

[20] Never, B., Betz, J. (2014). Comparing the climate policy performance of emerging economies. World Development, 59: 1-15. https://doi.org/10.1016/j.worlddev.2014.01.016

[21] Gerber, J.F. (2011). Conflicts over industrial tree plantations in the South: Who, how and why? Global Environmental Change, 21(1): 165-176. https://doi.org/10.1016/j.gloenvcha.2010.09.005

[22] Herring, R.J. (2010). Epistemic brokerage in the bioproperty narrative: contributions to explaining opposition to transgenic technologies in agriculture. New Biotechnology, 27(5): 614-622. https://doi.org/10.1016/j.nbt.2010.05.017

[23] Schapper, A. (2020). From the local to the global: learning about the adverse human rights effects of climate policies. Environmental Politics, 29(4): 628-648. https://doi.org/10.1080/09644016.2020.1743423

[24] Castillo, J., Jurado, J., Allen, S. (2008). Assessing the effect of social networks among Mexican enterprises, International Journal of Commerce and Management, 18(4): $331-343$ https://doi.org/10.1108/10569210810921951

[25] Dupuy, K.E. (2014). Community development requirements in mining laws. The Extractive Industries and $\quad$ Society, 200-215. https://doi.org/10.1016/j.exis.2014.04.007

[26] Quist, L.M., Nygren, A. (2015). Contested claims over space and identity between fishers and the oil industry in Mexico. Geoforum 63: 44-54. https://doi.org/10.1016/j.geoforum.2015.05.015

[27] Hadden, J., Jasny, L. (2017). The power of peers: How transnational advocacy networks shape NGO strategies on climate change. Brazilian Journal of Political Science, 49(2): https://doi.org/10.1017/S0007123416000582

[28] Yanguas, P., Hulme, D. (2015). Barriers to political analysis in aid bureaucracies: From principle to practice in DFID and the world bank. World Development, 74: 209-219. https://doi.org/10.1016/j.worlddev.2015.05.009

[29] Ciplet, D. (2017). Subverting the status quo? Climate debt, vulnerability and counter-hegemonic frame integration in United Nations climate politics - a 
framework for analysis. Review of International Political Economy, 24(6): $1052-1075$ https://doi.org/10.1080/09692290.2017.1392336

[30] Sippl, K. (2015). Private and civil society governors of mercury pollution from artisanal and small-scale gold mining: A network analytic approach. The Extractive Industries and Society, 2(2): 198-208. https://doi.org/10.1016/j.exis.2015.01.008

[31] Koslinski, M.C., Reis, E.P. (2009). Transnational and domestic relations of NGOs in Brazil. World Development, 37(3): 714-725. https://doi.org/10.1016/j.worlddev.2008.06.005

[32] Feldman, D.L. (2012). The future of environmental networks - Governance and civil society in a global context. Futures, 44(9): 787-796. https://doi.org/10.1016/j.futures.2012.07.007

[33] Heubaum, H., Biermann, F. (2015). Integrating global energy and climate governance: The changing role of the International Energy Agency. Energy Policy, 87: 229239. https://doi.org/10.1016/j.enpol.2015.09.009

[34] Vega, R.P. (2015). Transnational environmental activism in north America: wielding soft power through knowledge sharing? Review of Policy Research, 32(1): 146-162. https://doi.org/10.1111/ropr.12111

[35] Ratten, V., Ferreira, J., Fernandes, C. (2016). Entrepreneurial and network knowledge in emerging economies. Review of International Business and Strategy, 26(3): 392-409. https://doi.org/10.1108/RIBS11-2015-0076 